\title{
Mental Health of Adults Treated in Adolescence with Scoliosis-Specific Exercise Program or Observed for Idiopathic Scoliosis
}

\author{
Maciej Płaszewski, ${ }^{1}$ Igor Cieśliński, ${ }^{1}$ Roman Nowobilski, ${ }^{2}$ Tomasz Kotwicki, ${ }^{3}$ \\ Jacek Terech, ${ }^{4}$ and Mariusz Furgal ${ }^{5}$ \\ ${ }^{1}$ Faculty of Physical Education in Biała Podlaska, Institute of Physiotherapy, Warsaw University School of Physical Education, \\ Akademicka 2, 21-500 Biała Podlaska, Poland \\ ${ }^{2}$ Faculty of Health Sciences, Institute of Physiotherapy, Jagiellonian University, Michałowskiego 12, 31-126 Kraków, Poland \\ ${ }^{3}$ Department of Pediatric Orthopedics and Traumatology, University of Medical Sciences of Poznan, 28 Czerwca 1956r. No. 135/147, \\ 61-545 Poznań, Poland \\ ${ }^{4}$ Centre of Pulmonology and Thoracic Surgery, J. Fałata 2, 43-360 Bystra, Poland \\ ${ }^{5}$ Department of Psychiatry, Jagiellonian University Medical College, Kopernika 21A, 31-501 Kraków, Poland
}

Correspondence should be addressed to Maciej Płaszewski; plaszewski@wp.pl

Received 16 August 2013; Accepted 22 October 2013; Published 20 January 2014

Academic Editors: F. Giallauria and B. Unver

Copyright (C) 2014 Maciej Płaszewski et al. This is an open access article distributed under the Creative Commons Attribution License, which permits unrestricted use, distribution, and reproduction in any medium, provided the original work is properly cited.

Objective. To examine general mental health in adult males and females, who in adolescence participated in a scoliosis-specific therapeutic exercise program or were under observation due to diagnosis of scoliosis. Design. Registry-based, cross-sectional study with retrospective data collection. Methods. Sixty-eight subjects (43 women) aged 30.10 (25-39) years, with mild or moderate scoliosis (11-36 Cobb angle), and 76 (38 women) nonscoliotic subjects, aged 30.11 (24-38) years, participated. The time period since the end of the exercise or observation regimes was 16.5 (12-26) years. Beck Depression Inventory (BDI) and General Health Questionnaire (GHQ-28) scores were analyzed with the $\chi^{2}$ and $U$ tests. Multiple regression analyses for confounders were also performed. Results. Intergroup differences of demographic characteristics were nonsignificant. Scoliosis, gender, participation in the exercise program, employment, and marital status were associated with BDI scores. The presence of scoliosis and participation in the exercise program manifested association with the symptoms. Higher GHQ-28 "somatic symptoms" subscale scores interacted with the education level. Conclusions. Our findings correspond to the reports of a negative impact of the diagnosis of scoliosis and treatment on mental health. The decision to introduce a therapeutic program in children with mild deformities should be made with judgment of potential benefits, risks, and harm.

\section{Introduction}

Scoliosis, in its most frequent adolescent idiopathic form diagnosed in about $80 \%$ of the cases $[1,2]$, is the most prevalent orthopedic condition affecting children [2] and may have lasting consequences $[3,4]$. Adult deformities can be classified as progressive adolescent idiopathic, primary degenerative, de novo, or secondary degenerative scoliosis [1]. In the adult population, the prevalence of scoliosis may exceed $30 \%[1,3]$. It ranges from nearly $9 \%$ in 40 -year-olds to $68 \%$ in 70 -year-olds [5] and increases almost linearly from the 6 th to the 8 th decade of life [6]. In contrast to adolescents, no associations with gender have been observed in adults [13].

Spine deformity may significantly influence the general health and patient's self-reported health-related quality of life (HRQoL), with a poor correlation between the radiographic and clinical findings $[2,3,7]$. Limitations in participation in social life and intimate relationships, lower marriage rates, fear of injury, poor self-perception, difficulties on the labor 
market, and mental disorders have been reported [1-3, 7]. Surgery or brace treatment may also lead to psychological side effects [3, 4, 8, 9]. Long-term outcome reports [10], including the Iowa [11], Montreal [12], and Göteborg [4, 13] series, suggested that deformity causes psychopathological effects or demonstrated positive coping mechanisms $[3,12]$. Furthermore, the available papers focus on the assessment of health-related quality of life and utilize generic (typically the SF-36 or WHOQOLBREF questionnaires) or conditionspecific (e.g., the Scoliosis Research Society (SRS)-22 questionnaire) measures with their physical, social, and emotional roles, mental functioning, bodily pain, and body image components, incorporated to produce a measure of a person's perceived general health status [5, 7]. Moreover, there are only few short-term reports comparing men and women $[10$, 14]. Also, we found no reports on scoliosis-specific exercises in the context of mental health and well-being, although physical exercises in the treatment of scoliosis remain a matter of debate [15] and high-level evidence for or against these procedures is lacking [16].

To our best knowledge, there has been no investigation utilizing the Beck Depression Inventory (BDI) and the Goldberg General Health Questionnaire (GHQ) in patients with scoliosis, despite the fact that these instruments are highly popular and widely used in primary health care settings and general populations [17].

Therefore, the aim of our study was to examine general mental health in young adult men and women, who in adolescence participated in a specific therapeutic exercise program or were under observation due to diagnosis of idiopathic scoliosis. We tested the null hypothesis that the participation in scoliosis-specific exercise regime in adolescence is not associated with mental health and well-being in adult life.

To improve the quality of reporting, we followed the recommendations of Strengthening the Reporting of Observational Studies in Epidemiology (STROBE) statement [18].

\section{Methods}

2.1. Study Design and Participants. We recruited participants by a cross-sectional evaluation from the population of subjects examined for scoliosis at the centre of Corrective and Compensatory Gymnastics, Bielsko-Biala, Poland. The Centre provides scoliosis screening for schoolchildren from the urban and suburban population of about 300000 . We analyzed the medical records of 5017 children examined between 1984 and 1995. We considered eligible registries of those children in whom observation or exercise program were recommended, while bracing and/or surgical treatment was exclusion criteria. Because of financial and technical limitations, we based our study on a sample of subjects. For that reason, we subsequently randomly selected 250 registries. We performed a simple random sampling and used a random numbers table for that purpose.

The largest of the previous observational studies in adults, who in adolescence were braced or treated surgically or observed, included 1476 patients and 1755 controls [12], while other major studies included 145 surgically treated, 127 braced, and 100 control subjects [4] and 40 observed and 37 braced patients [13]. Response rates in those, and other studies, described by Goldberg et al. [12], ranged from $48 \%$ to $89 \%$. Therefore, based on our pilot study, we presumed to enroll at least $60 \%$ of potential participants. Comparing to the analyzed studies we assumed that this sample size was sufficient for the study with a margin of error of $3 \%$ and a $95 \%$ confidence level, based on an actual estimate of $50 \%$. We made every effort to locate the subjects and, if they changed their addresses, we attempted to retrieve the current addresses or telephone numbers from their parents or other inhabitants or collected further relevant information, for example, about migration. We applied the procedures recommended to increase participation (we published an invitation letter in a local free newspaper, provided personalized introductory letters, and made follow-up telephone calls to nonrespondents) [19]. We managed to locate 164 potential participants, of whom 15 were ineligible due to severe scoliosis $(n=6)$, recent X-ray exposure $(n=$ $1)$, mental condition $(n=1)$, history of treatment of depression or other psychological disorders $(n=2)$. Five people were excluded due to noncompliance with treatment regimen (the rate of absence from exercise sessions exceeding $20 \%$, based on patients' records). Of 149 participants finally included in the study, 2 dropped out and 3 did not return the questionnaires. Thus, a total of 144 (57.6\%) of the initially selected subjects completed the study. The flow of recruitment and the selection criteria are presented in detail in Figure 1.

Mean age at diagnosis was 10.5 (range 9-16) years for the whole group, and treatment started for subjects aged 10.7 (916) years. The regime involved scoliosis-specific, symmetrical, strengthening, antigravity, and elongating exercises of the postural muscles, performed in group during 45-minute gym sessions twice a week and individually at home (sets of 1215 exercises, 30-45 minutes a day). Subjects who did not participate in the exercise program were observed for three to five years on the basis of scheduled follow-up orthopedic examinations. Follow-up period since the termination of treatment was 16.5 (12-26) years for the whole group, 17.1 (12$25)$ years for the exercising group, and 15.9 (12-23) years for the observed subjects. The differences in the distribution of variables were nonsignificant (Table 1).

2.2. Curve Measurements. Two specialists independently measured the magnitude of the curvature according to the Cobb method [20], on a full-length anteroposterior radiograph, and then a consensus was reached. On this basis, we divided participants into two groups: persons with mild (11-24 Cobb) or moderate $\left(25-44^{\circ}\right.$ Cobb) scoliosis and nonscoliotic participants (Tables 1 and 2 ).

2.3. Outcome Measures. The BDI, in its long form, is a 21item self-reported measure, with items rated 0 to 3 (most severe signs and symptoms) [17]. We applied the BDI-I in its Polish adaptation [21] and interpreted the results according to the classification proposed for this version [22]: $0-4$ no or minimal, 5-13 mild/low, 14-20 moderate/medium, and $\geq 21$ severe depression. We additionally analyzed the results with 


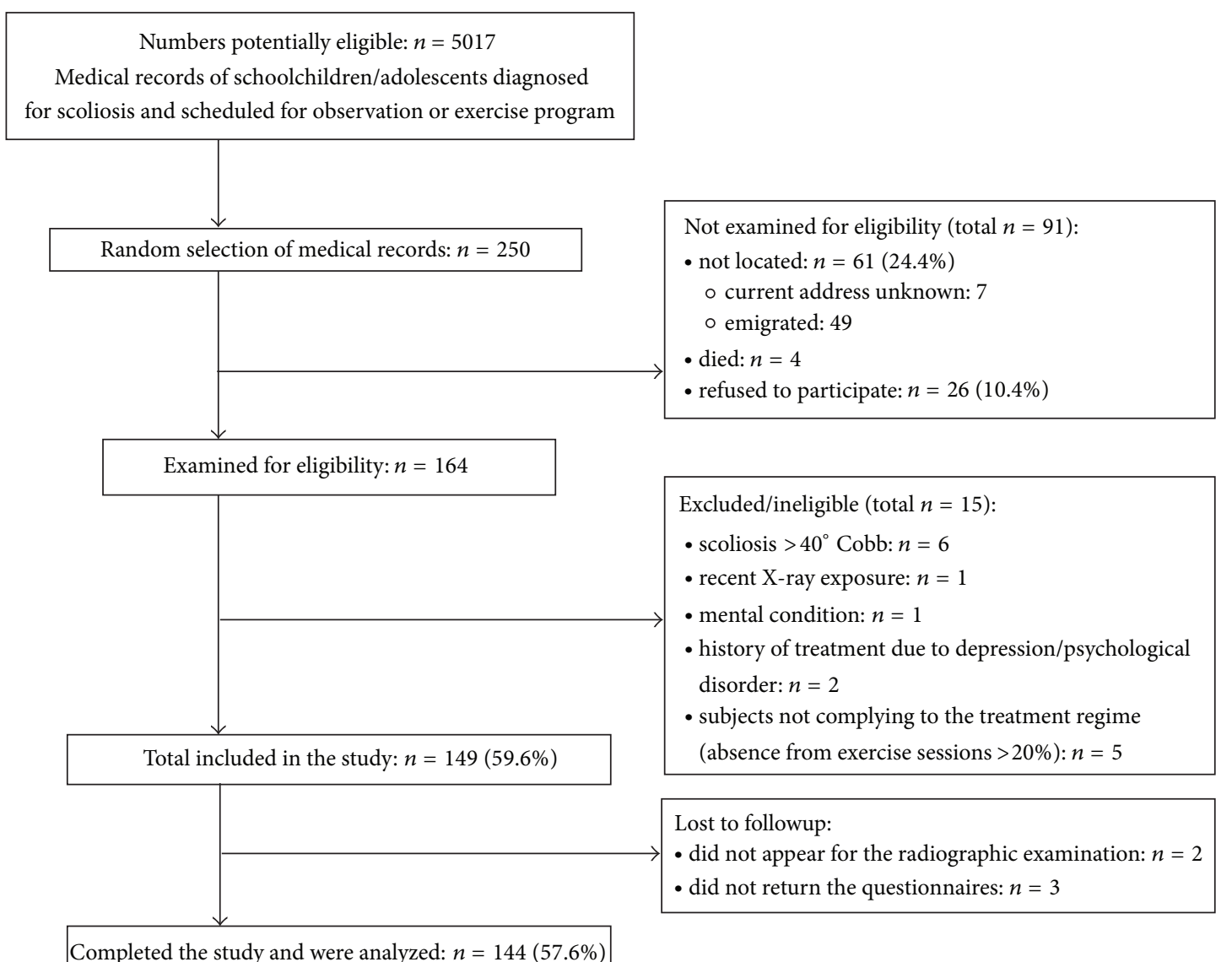

FIGURE 1: The process of recruiting participants.

respect to the proposed 10-point threshold for depression [23]. Subjects responded on a seven-day recall basis, so that we obtained results reflecting a trait rather than a state. Only the total score can typically be interpreted. However, because interesting single-symptom comparisons had been conducted [24], we also performed such analyses.

The assessment of depression alone can be oversimplified, as many depressive symptoms can be the expression of the condition itself [25]. Thus, we decided to use Beck's BDI for the assessment of depressive mood experienced in a recent period of time, because it contains (unlike other scales) relatively few symptoms that can be ascribed to the somatic state of patients. For the assessment of potential psychiatric morbidity of a wider spectrum, we applied the GHQ-28. Apart from depression, the tool assesses somatisation, hypochondriasis, anxiety, sleep, and social functioning disorders.

The GHQs are self-administered instruments designed to detect a probable psychiatric disorder. Different versions have been developed, with the most widely used 28-item GHQ$28[17,26]$, validated into the Polish context, and available in Polish version, published in Poland [27]. The GHQ-28 consists of four subscales: "somatic symptoms," "anxiety and insomnia," "social dysfunction," and "severe depression" [26, 27]. The results are interpreted within a given group and in accordance with the maximum possible scores (21 in domains and 84 general total in the Likert scale).

2.4. Statistics. We used descriptive statistics for the demographic and clinical characteristics of the subjects. The maximum-likelihood chi-square test was used to assess intergroup differences for subsequent characteristics and individual BDI symptoms, while the Mann-Whitney $U$ test was used for categorical data (BDI and GHQ-28 total and GHQ-28 domains). To examine the interaction between the BDI scores (as categorical data) and a number of confounders (Table 5), we employed the count data regression model zeroinfl()/hurdle(), from the PSCL package [28, 29]. We chose that model because the total BDI scores were dispersed, the number of zero scores was considerably large, and, additionally, the distribution of the remaining scores (after the exclusion of zero scores from the analysis) was close to the Poisson distribution. The GHQ-28 scores were free from such constraints; therefore, we used the polr( ) function of the MASS package-the logit model for ordinal variables [30].

\section{Results}

Median total BDI scores of both scoliotic and nonscoliotic groups (4.60 and 5.89, resp., $P=.77$ ) were within the category 
TABLE 1: Characteristics of the participants and intergroup differences.

\begin{tabular}{|c|c|c|c|c|}
\hline Factor or domain & $\begin{array}{c}\text { Total group } \\
(n=144)\end{array}$ & $\begin{array}{c}\text { Unaffected } \\
(n=76)\end{array}$ & $\begin{array}{c}\text { Scoliotic } \\
(n=68) \\
\end{array}$ & $P$ \\
\hline Age & $\begin{array}{c}30.11 \pm 4.11(24- \\
39) \\
30\end{array}$ & $\begin{array}{c}30.11 \pm 3.99(24- \\
38) \\
30\end{array}$ & $\begin{array}{c}30.10 \pm 4.67(25- \\
39) \\
30\end{array}$ & .98 \\
\hline Women $(n)$ & 81 & 38 & 43 & .10 \\
\hline \multicolumn{5}{|l|}{ Place of residence $(n)$} \\
\hline Rural & 8 & 5 & 3 & \multirow{4}{*}{.18} \\
\hline Urban $\leq 20000$ & 1 & 0 & 1 & \\
\hline Urban $20000-50000$ & 2 & 0 & 2 & \\
\hline Urban > 50000 & 133 & 71 & 62 & \\
\hline \multicolumn{5}{|l|}{ Marital status ( $n$ ) } \\
\hline Single & 75 & 35 & 40 & \multirow{2}{*}{.17} \\
\hline Married/living together & 69 & 41 & 28 & \\
\hline \multicolumn{5}{|l|}{ Education $(n)$} \\
\hline Vocational & 11 & 5 & 6 & \multirow{3}{*}{.88} \\
\hline Preuniversity/college & 34 & 18 & 16 & \\
\hline University & 99 & 53 & 46 & \\
\hline \multicolumn{5}{|l|}{ Intervention $(n)$} \\
\hline Observation & 73 & 41 & 32 & \multirow{2}{*}{.37} \\
\hline Exercises & 71 & 35 & 36 & \\
\hline Scoliosis in immediate family $(n)$ & 48 & 23 & 25 & .40 \\
\hline
\end{tabular}

Data for age are presented as mean \pm SD (range), median.

TABLE 2: Clinical characteristics of the participants with scoliosis.

\begin{tabular}{|c|c|c|c|c|c|c|c|}
\hline \multirow[b]{2}{*}{$\begin{array}{l}\text { Curve size }\left({ }^{\circ} \text { Cobb }\right) \\
(n=68)\end{array}$} & \multicolumn{2}{|c|}{ Curve severity $(n,(\%))$} & \multicolumn{3}{|c|}{ Curve location $(n,(\%))$} & \multicolumn{2}{|c|}{ Scoliosis type $(n,(\%))$} \\
\hline & $\begin{array}{c}\text { 11-2 } 4^{\circ} \text { Cobb } \\
\text { (mild) }\end{array}$ & $\begin{array}{c}25-40^{\circ} \text { Cobb } \\
\text { (moderate) }\end{array}$ & $\begin{array}{c}\text { Single } \\
\text { primary Th }\end{array}$ & $\begin{array}{c}\text { Single } \\
\text { primary } \\
\text { Th-L or L }\end{array}$ & $\begin{array}{l}\text { Double } \\
\text { major }\end{array}$ & $\begin{array}{l}\text { Early-onset } \\
\text { idiopathic }^{*}\end{array}$ & $\begin{array}{l}\text { Adolescent } \\
\text { idiopathic }{ }^{* *}\end{array}$ \\
\hline $15.16 \pm 6.44(11-36)$ & $62(92)$ & $6(8)$ & $9(13)$ & $45(66)$ & $14(25)$ & $11(16)$ & $57(74)$ \\
\hline
\end{tabular}

Curve size expressed as mean \pm SD (range); ${ }^{*} 9$ years of age; ${ }^{* *} 10-16$ years of age; Th: thoracic and L: lumbar.

of mild depression [22]. Both groups differed significantly in the distribution into the categories of minimal, mild, moderate, and severe depression $(P<.01)$, with more scoliotic than nonscoliotic participants showing depressive symptoms ( $45 \%$ and $33 \%$ of subjects, resp.). The differences between the subjects with mild and moderate deformities were also significant $(P<.05)$, with a greater tendency for depressive symptoms in subjects with milder deformities. Only 11 (14\%) nonscoliotic and 7 (10\%) scoliotic participants exceeded the 10-point threshold. The results are shown in Table 3, and Figure 2 illustrates individual BDI symptoms.

Intragroup gender differences were nonsignificant for both the total BDI score and the categories of depression severity. Nonetheless, more women than men exceeded 10 points, irrespective of the group (Table 4). Figures 3(a) and 3(b) illustrate additional comparisons of the individual symptoms between men and women.

We obtained low scores of the GHQ-28 domains, with the highest scores of "anxiety/insomnia" both in scoliotic
(3.99, 19\% maximum) and in unaffected individuals (3.46, $16.5 \%$ maximum). Differences between both groups and between subjects with mild and moderate scoliosis were nonsignificant (Table 3 and Figure 4(c)).

Table 4 and Figure 4 demonstrate intergroup comparisons of the GHQ-28 subscales. The differences were significant only in the "somatic symptoms" subscale for intragroup gender comparisons in the nonscoliotic group, with lower scores in men $(P<.05)$. In all comparisons, the overall mean and median values were far below the maximum possible results. None of the scores exceeded the figures of 11 for the subscales, which may be considered as achieving "caseness" [26].

For the multiple regression analysis for both BDI and GHQ-28-with the total score and subsequent domains analyzed-we included age, gender, presence of scoliosis $\left(>10^{\circ} \mathrm{Cobb}\right)$, treatment type (exercise regime versus observation), marital status, employment, level of education, and presence of scoliosis in relatives as potential confounders. We 
TABLE 3: BDI and GHQ-28 scores-intergroup and intragroup comparisons.

\begin{tabular}{|c|c|c|c|c|c|c|c|}
\hline \multirow[b]{2}{*}{ Measures and domains } & \multirow{2}{*}{$\begin{array}{l}\text { Total group } \\
(n=144)\end{array}$} & \multirow{2}{*}{$\begin{array}{l}\text { Unaffected } \\
(n=76)\end{array}$} & \multirow{2}{*}{$\begin{array}{l}\text { Scoliotic } \\
(n=68)\end{array}$} & \multirow[b]{2}{*}{$P$} & \multicolumn{2}{|c|}{ Scoliotic } & \multirow[b]{2}{*}{$P$} \\
\hline & & & & & $\begin{array}{c}11-24^{\circ} \text { Cobb } \\
(n=62)\end{array}$ & $\begin{array}{c}25-40^{\circ} \mathrm{Cobb} \\
(n=6)\end{array}$ & \\
\hline \multicolumn{8}{|l|}{$B D$} \\
\hline Total score & $\begin{array}{c}4.56 \pm 5.31 \\
(0-36), 3\end{array}$ & $\begin{array}{c}4.68 \pm 5.89(0- \\
36) \\
3\end{array}$ & $\begin{array}{c}4.43 / 3 / 4.60 / 0- \\
15\end{array}$ & .77 & $\begin{array}{l}4.45 \pm 4.57 \\
(0-13), 3\end{array}$ & $\begin{array}{l}4.17 \pm 5.46 \\
(0-10), 1.5\end{array}$ & .95 \\
\hline \multicolumn{8}{|l|}{ Symptoms (n (\%)) } \\
\hline Minimum & $88(61)$ & $51(67)$ & $37(54)$ & \multirow{4}{*}{$<.01^{*}$} & $33(53)$ & $4(67)$ & \multirow{4}{*}{$<.05^{*}$} \\
\hline Mild & $48(33)$ & $18(24)$ & $30(44)$ & & $28(45)$ & $2(33)$ & \\
\hline Moderate & $6(4)$ & $6(8)$ & 0 & & 0 & 0 & \\
\hline Severe & $2(1)$ & $1(1)$ & $1(1)$ & & $1(2)$ & 0 & \\
\hline$>10$-point threshold & $18(13)$ & $11(14)$ & $7(10)$ & - & $6(10)$ & $1(17)$ & - \\
\hline \multicolumn{8}{|l|}{ GHQ-28 } \\
\hline A: somatic symptoms & $\begin{array}{c}5.36 \pm 2.64(0- \\
13) \\
5\end{array}$ & $\begin{array}{c}5.32 \pm 2.70(0- \\
13) \\
5\end{array}$ & $\begin{array}{c}5.41 \pm 2.59(0- \\
11) \\
5\end{array}$ & .82 & $\begin{array}{l}5.48 \pm 2.55 \\
\quad(1-11), 5\end{array}$ & $\begin{array}{c}4.67 \pm 3.14(0- \\
9) \\
4.5\end{array}$ & .75 \\
\hline B: anxiety, insomnia & $\begin{array}{c}4.95 \pm 3.74(0- \\
17) \\
4\end{array}$ & $\begin{array}{c}4.91 \pm 3.99(0- \\
16) \\
4\end{array}$ & $\begin{array}{c}5.00 \pm 3.46 \\
(0-17), 5\end{array}$ & .88 & $\begin{array}{l}5.00 \pm 3.46 \\
(0-17), 5\end{array}$ & $\begin{array}{c}5.00 \pm 3.74(0- \\
10) \\
5\end{array}$ & .99 \\
\hline $\begin{array}{l}\text { C: functional disorders, } \\
\text { social dysfunction }\end{array}$ & $\begin{array}{c}6.83 \pm 1.98 \\
(0-14), 7\end{array}$ & $\begin{array}{c}6.95 \pm 2.08 \\
(0-14), 7\end{array}$ & $\begin{array}{c}6.69 \pm 1.87 \\
(1-13), 7\end{array}$ & .44 & $\begin{array}{l}6.73 \pm 1.93 \\
(1-13), 7\end{array}$ & $\begin{array}{c}6.33 \pm 1.03(5- \\
7) \\
7\end{array}$ & .67 \\
\hline D: depressive symptoms & $\begin{array}{c}1.09 \pm 2.19 \\
(0-14), 0\end{array}$ & $\begin{array}{l}1.01 \pm 2.14 \\
(0-13), 0\end{array}$ & $\begin{array}{l}1.18 \pm 2.26 \\
(0-14), 0\end{array}$ & .65 & $\begin{array}{c}1.01 \pm 2.14 \\
(0-16), 0\end{array}$ & $\begin{array}{c}1.13 \pm 2.33(0- \\
3) \\
0\end{array}$ & .77 \\
\hline Total score $(A+B+C+D)$ & $\begin{array}{c}18.01 \pm 8.65 \\
(0-56), 16\end{array}$ & $\begin{array}{c}18.01 \pm 9.26 \\
(0-54), 16\end{array}$ & $\begin{array}{c}18.01 \pm 7.98 \\
(0-56), 17.5\end{array}$ & .99 & $\begin{array}{c}18.05 \pm 8.15(4- \\
56) \\
18 \\
\end{array}$ & $\begin{array}{c}17.67 \pm 6.62(11- \\
21), \\
16.5\end{array}$ & .99 \\
\hline
\end{tabular}

Data for BDI total scores and GHQ-28 are presented as mean \pm SD (range), median.

BDI depressive symptoms: minimum (0-4 pts), mild (5-13 pts), moderate (14-20 pts), and severe ( $\geq 21 \mathrm{pts})$.

${ }^{*}$ Significant difference.

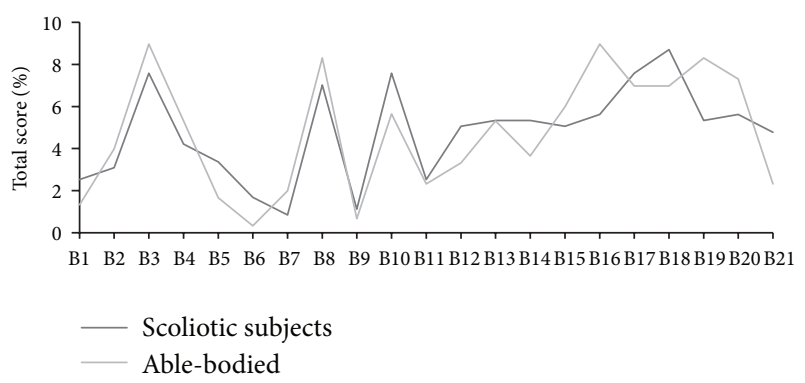

FIGURE 2: Scores of individual BDI symptoms in groups. BDI items: B1: mood; B2: pessimism; B3: sense of failure; B4: lack of satisfaction; B5: guilt feelings; B6: sense of punishment; B7: self-dislike; B8: selfaccusation; B9: suicidal wishes; B10: crying; B11: irritability; B12: social withdrawal; B13: indecisiveness; B14: distortion of body image; B15: work inhibition; B16: sleep disturbance; B17: fatigability; B18: loss of appetite; B19: weight loss; B20: somatic preoccupation; B21: loss of libido.

only report findings with significant or nearly significant differences (Table 5). Therefore, for the GHQ-28, only domain A (somatic symptoms) is presented.
Gender, employment, and marital status were associated with BDI results (Table 5$)$. Being male (.83 odds ratio, OR, $.71-.98$ confidence interval, CI), single (.82 OR, .68-.96 CI), employed (.80 OR, .54-.92 CI), and having lower level of education $(.70 \mathrm{OR}, .62-.79 \mathrm{CI})$ seemed to decrease the tendency for depression, while the presence of scoliosis (.84 OR, $.72-1.00 \mathrm{CI})$ and participation in the exercise program (1.16 OR, .90-1.38 CI) manifested association with the symptoms. The difference was not significant $(P=.06)$, but taking into account a considerably low power of the study ( 0.16 for BDI and 0.10 for GHQ-28, a posteriori) and the risk for type II error, we cautiously considered these findings as indicating a possible tendency.

We found a significant negative interaction $(P<.05)$ between the level of education and somatic symptoms in GHQ-28 subscale A (.52 OR, .33-.85 CI). Also, being male seemed to be negatively associated with the tendency towards somatization $(P=1.87$, where $P=2.00$ is the minimum level of significance). In general, with lesser confidence (nonsignificant associations but with high odds ratios), the multiple regression for the GHQ-28 scores confirms the BDI findings. 
TABLE 4: Women versus men within the subgroups.

\begin{tabular}{|c|c|c|c|c|c|c|}
\hline \multirow[b]{2}{*}{ Measures and domains } & \multicolumn{3}{|c|}{ Unaffected } & \multicolumn{3}{|c|}{ Scoliotic } \\
\hline & Women $(n=38)$ & $\operatorname{Men}(n=38)$ & $P$ & Women $(n=43)$ & $\operatorname{Men}(n=25)$ & $P$ \\
\hline \multicolumn{7}{|l|}{$B D I$} \\
\hline Total score & $\begin{array}{c}4.79 \pm 5.13 \\
(0-26), 3\end{array}$ & $\begin{array}{c}4.58 \pm 5.89 \\
(0-36), 3\end{array}$ & .87 & $\begin{array}{l}4.70 \pm 5.17 \\
(0-13), 3\end{array}$ & $\begin{array}{c}3.96 \pm 3.48 \\
(0-15), 4\end{array}$ & .52 \\
\hline \multicolumn{7}{|l|}{ Symptoms (n (\%)) } \\
\hline Minimum & $23(61)$ & $28(74)$ & \multirow{4}{*}{.33} & $23(53)$ & $14(56)$ & \multirow{5}{*}{.63} \\
\hline Mild & $11(29)$ & $7(18)$ & & $19(44)$ & $11(44)$ & \\
\hline Moderate & $4(11)$ & $2(5)$ & & 0 & 0 & \\
\hline Severe & 0 & $1(3)$ & & $1(2)$ & 0 & \\
\hline$>10$-point threshold & $7(18)$ & $4(11)$ & - & $6(14)$ & $1(4)$ & \\
\hline \multicolumn{7}{|l|}{ GHQ-28 } \\
\hline A: somatic symptoms & $\begin{array}{l}5.97 \pm 2.69 \\
(2-12), 5\end{array}$ & $\begin{array}{l}4.66 \pm 2.58 \\
(2-14), 4\end{array}$ & $<.05^{*}$ & $\begin{array}{l}5.44 \pm 2.75 \\
\quad(0-11), 5\end{array}$ & $\begin{array}{l}5.36 \pm 2.34 \\
(3-10), 5\end{array}$ & .90 \\
\hline B: anxiety, insomnia & $\begin{array}{l}5.47 \pm 4.28 \\
(0-16), 5\end{array}$ & $\begin{array}{c}4.34 \pm 3.66 \\
(0-14), 4\end{array}$ & .21 & $\begin{array}{c}5.19 \pm 3.68 \\
(0-16), 5\end{array}$ & $\begin{array}{l}4.68 \pm 3.08 \\
(0-10), 5\end{array}$ & .56 \\
\hline $\begin{array}{l}\text { C: functional disorders, } \\
\text { social dysfunction }\end{array}$ & $\begin{array}{c}7.29 \pm 2.04 \\
(6-14), 7\end{array}$ & $\begin{array}{c}6.61 \pm 2.09 \\
(6-14), 7\end{array}$ & .15 & $\begin{array}{c}6.67 \pm 1.85(2-13) \\
7\end{array}$ & $\begin{array}{l}6.72 \pm 1.95 \\
(1-11), 7\end{array}$ & .92 \\
\hline D: depressive symptoms & $\begin{array}{c}1.13 \pm 2.07 \\
(0-7), 0\end{array}$ & $\begin{array}{c}.89 \pm 2.23 \\
(0-13), 0\end{array}$ & .63 & $\begin{array}{c}1.30 \pm 2.67 \\
(0-16), 0\end{array}$ & $\begin{array}{c}.96 \pm 1.31 \\
(0-5), 0\end{array}$ & .55 \\
\hline Total score $(A+B+C+D)$ & $\begin{array}{c}19.53 \pm 9.36 \\
(6-37), 17\end{array}$ & $\begin{array}{l}16.5 \pm 9.02 \\
(0-54) 14.5\end{array}$ & .15 & $\begin{array}{c}18.60 \pm 8.47 \\
(9-56), 17\end{array}$ & $\begin{array}{c}17.00 \pm 7.14 \\
(9-29), 17\end{array}$ & .42 \\
\hline
\end{tabular}

Data for BDI total scores and GHQ-28 are presented as mean \pm SD (range), median.

BDI depressive symptoms: minimum (0-4 pts), mild (5-13 pts), moderate (14-20 pts), and severe ( $\geq 21 \mathrm{pts})$.

${ }^{*}$ Significant difference.

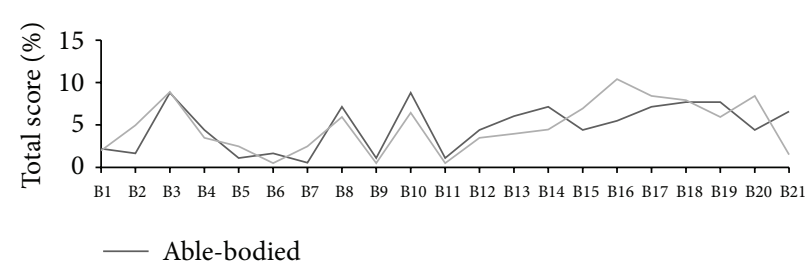

(a) Women

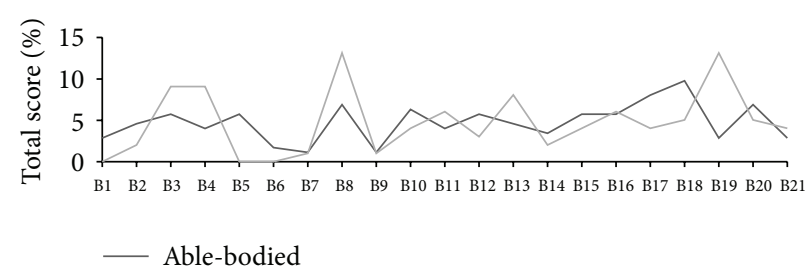

(b) Men

FIGURE 3: Scores of individual BDI symptoms-scoliotic and unaffected women (a) and men (b). Individual symptoms (B1-B2) are labelled in Figure 2.

\section{Discussion}

There are no set thresholds for the interpretation of the GHQ28 scores, but nonetheless both the total and domain scores in the scoliotic and nonscoliotic groups were below the 11point threshold of possible "caseness" [26]. Furthermore, the intragroup comparisons revealed that the GHQ-28 scores did not differ significantly between subjects with mild and moderate spine deformities (Table 3 ). The more specified analysis with the BDI confirmed that scoliotic subjects manifested more apparent depressive symptoms, irrespective of the severity of the deformity (Table 4 ). Considering that mild deformities are typically unnoticeable, it seems that it is the awareness of the deformity and not the physical manifestation itself that may play a role here. The multiple regression analyses (the zero inflation model for BDI and the logit model for ordinal variables for GHQ-28) confirmed these observations (Table 5). We found a significant association between depressive symptoms and the presence of spine deformity $(P<.05)$. Depression can be an understandable response to loss and injuries to self-esteem associated with the diagnosis established in adolescence, which is the most vulnerable period for the formation of adult identity [25, 31]. The diagnostic label itself can have a significant influence on the patient's behaviour and emotions, even if there are no symptoms or diseases. Other factors for an increased risk of emotional disorders can be social stigmatization and exclusion associated with participation in a rehabilitation program [31].

There are no results available from similar studies regarding adults with a history of participation in scoliosis-specific exercise programs, but studies on adolescent patients treated 


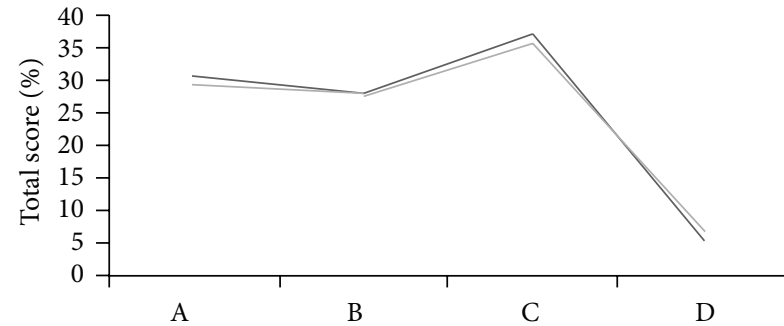

(a) Women

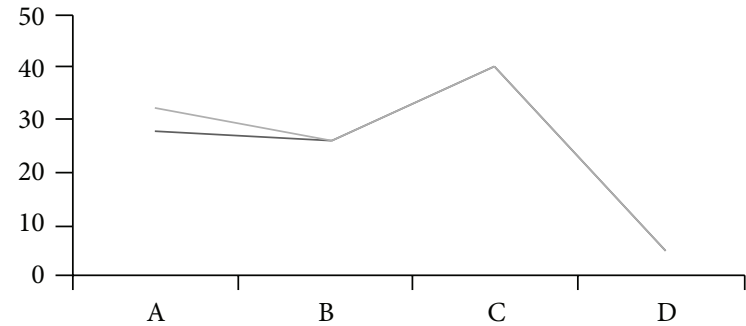

(b) Men

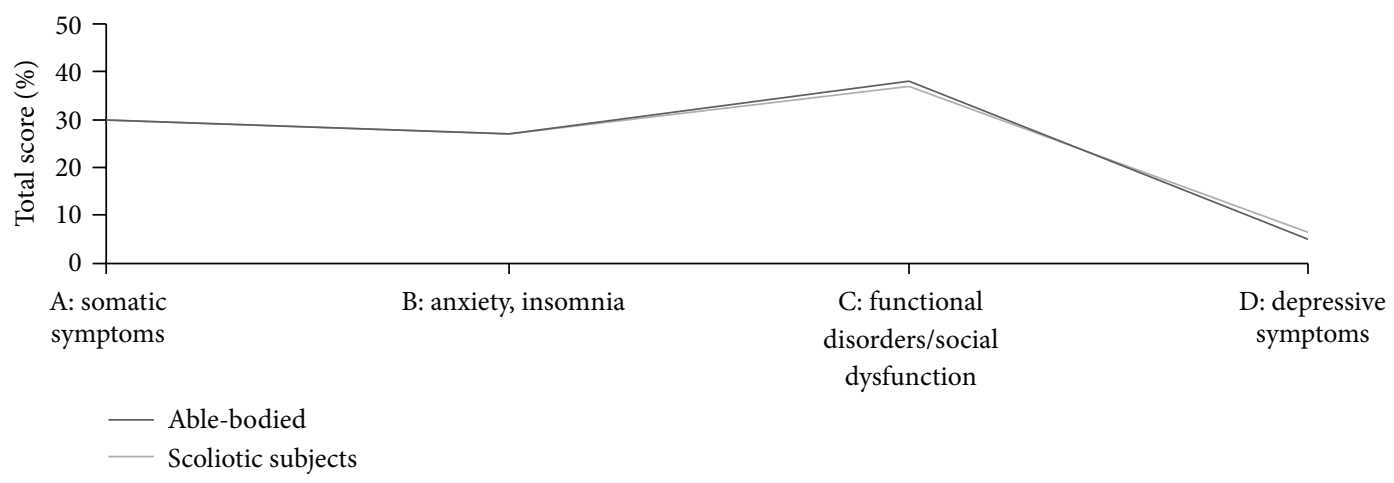

(c) Women and men

FIGURE 4: GHQ-28 subscales—scoliotic versus unaffected women (a), men (b), and women and men (c).

TABLE 5: Multiple regression analysis for BDI (the zero inflation model) and GHQ-28 (the logit model for ordinal variables).

\begin{tabular}{|c|c|c|c|c|c|}
\hline Total BDI score & $\begin{array}{c}\text { Parameter } \\
\text { estimate }\end{array}$ & $\begin{array}{c}\text { Standard } \\
\text { error }\end{array}$ & $P$ & Odds ratio & $95 \% \mathrm{CI}$ \\
\hline Gender (male) & -.18 & .08 & $<.05^{*}$ & .83 & $.71-.98$ \\
\hline Scoliosis $\left(<10^{\circ}\right.$ Cobb $)$ & -.16 & .08 & $<.05^{*}$ & .84 & $.72-1.00$ \\
\hline Intervention (observation) & .15 & .08 & .06 & 1.16 & $.90-1.38$ \\
\hline Marital status (single) & -.21 & .08 & $<.01^{*}$ & .82 & $.68-.96$ \\
\hline Employment (employed) & -.35 & .13 & $<.01^{*}$ & .80 & $.54-.92$ \\
\hline Education (lower level) & -.35 & .05 & $<.001^{*}$ & .70 & $.62-.79$ \\
\hline Scoliosis in immediate family (occurring) & -.11 & .08 & .15 & .89 & $.75-1.06$ \\
\hline GHQ-28 domain $\mathrm{A}^{*}$ : somatic symptoms & $\begin{array}{c}\text { Parameter } \\
\text { value }\end{array}$ & $\begin{array}{c}\text { Standard } \\
\text { error }\end{array}$ & $|t|$ & Odds ratio & $95 \%$ CI \\
\hline Age (older) & -.02 & .03 & .55 & .97 & $.91-1.05$ \\
\hline Gender (male) & -.56 & .30 & 1.87 & .56 & $.31-1.02$ \\
\hline Scoliosis $\left(<10^{\circ} \mathrm{Cobb}\right)$ & .06 & .29 & .43 & 1.13 & $.64-2.03$ \\
\hline Intervention (observation) & .18 & .30 & .59 & 1.19 & $.66-2.18$ \\
\hline Marital status (single) & .37 & .30 & 1.21 & 1.45 & $.80-2.67$ \\
\hline Employment (unemployed) & -.64 & .45 & 1.33 & .52 & $.21-1.28$ \\
\hline Education (lower level) & -.64 & .24 & $\begin{array}{c}2.62 \\
P<.05^{* *}\end{array}$ & .52 & $.33-.85$ \\
\hline Scoliosis in immediate family (occurring) & -.003 & .32 & .01 & .99 & $.53-1.87$ \\
\hline
\end{tabular}

${ }^{*}$ For GHQ-28 global total and domains B, C, and D no associations were found; thus, results are not shown. For BDI $r^{2}$ was not calculated, as the zero inflated model of regression analysis was used. For GHQ-28 McFadden pseudo $r^{2}=13.65$.

${ }^{* *}$ Significant difference. 
with a brace indicate that scoliosis and therapy are significant risk factors for depression, suicidal thoughts, worry and concern over body development and appearance, and peer reactions, not only in girls, but also in boys [32]. Outcome studies on adults are less consistent. Nonsignificant effects on emotional reactions and mental health have been observed [3, $4,8]$, and patients did not experience psychological distress or presented good coping mechanisms [12,32]. The scores of the mental health component of the SF-36 quality of life questionnaire in surgically treated subjects were lower than the reference values, with the findings largely independent of age, curve type and severity, and the presence and magnitude of trunk deformity [33]. Adult subjects, mostly women, who had undergone a surgery in adolescence, were content with their lives but tended to start families later in life and had fewer and less satisfying sexual relationships than ageand sex-matched controls. Interestingly, in line with our findings, these outcomes were associated with the level of education [34]. Nonetheless, the findings from studies on surgically treated patients cannot be directly compared to our observations.

We observed a tendency for depressive symptoms associated with the participation in the exercise program. This finding is, on the surface, in opposition to the assumptions about the beneficial effect of exercising on mental health. Physical activity has been shown to be associated with decreased symptoms of depression and anxiety, life satisfaction, cognitive functioning, and psychological well-being. In contrast, physical inactivity is believed to be associated with the development of psychological disorders, and exercise and exercise training are considered as a treatment of depression $[35,36]$. With limited evidence, people with scoliosis are encouraged to participate in physical and sports activities for the psychosocial and emotional benefits of exercising $[37,38]$. However, scoliosis-specific exercise programs are not considered as physical activity due to their intentional use as a therapeutic intervention rather than leisure activity $[37,38]$. Our findings also suggest that the regime of scoliosis-specific exercises is a treatment intervention, not an exercise as such. As we observed, participation in a scoliosis-specific exercise program may be associated with depressive symptoms later in life. However, our results cannot be directly balanced with any available evidence.

The multiple regression analysis revealed an adverse association of male gender with the tendency for depression $(P<.05)$ and somatization $(P=1.87$ in the logit model for ordinal variables). The latter finding corresponds with the observation from intragroup comparisons: more women, irrespective of the group, had BDI scores greater than 10 points, considered in some interpretations as a threshold of depression [23], and the only significant difference in the GHQ-28 was that of higher scores in nonscoliotic women in the "somatic symptoms" domain (Table 4). In general, rates of depression are higher and outcomes tend to be worse in women compared with men [39]. However, as regards people with scoliosis, our results can be compared only with the few available reports. Findings of a better perception of body image in scoliotic men have been reported in the SteJustine cohort study [12] and in a small study on braced adolescents [9]. Transient psychological effects were present during treatment in braced young adult women, and more prevalent body image disruptions in their surgically treated peers were found during the mean follow-up of seven years [10]. Nonsignificant differences between men and women fourteen years after surgery were also reported [14].

Lower level of education and being employed, unlike the family history of scoliosis, were shown to be associated with a lower tendency for depression. These observations confirm that we have to be cautious in drawing firm conclusions from this cross-sectional analysis, and that the reported associations are affected by confounding factors, which is typical for observational studies investigating real-life phenomena.

Because it was an uncontrolled observational study with a long follow-up of 16.5 years, we cautiously analyzed the obtained data with respect to limitations of the method and a number of potential confounding factors. Also, to reduce selection bias, we identified the eligible participants by applying a registry-based procedure, comprising the records of subjects from the entire local population of children and adolescents, and used a systematic procedure of random selection of the records. Participants did not differ significantly in demographic (Table 1) and clinical (Table 2) characteristics. Thus, we assume that these findings are not limited to the studied population. Nonetheless, in the sample of 144 participants, a potential selection bias resulting from refusals to participate and factors such as migration and unavailability of selected cases may limit the strength of our findings. Also, the reference values and set thresholds are lacking for both GHQ-28 and BDI, which is indicated as limitation of this instrument $[17,23]$. For the availability of the Polish version, we applied the BDI-I and, accordingly, different thresholds from those proposed for the BDI-II. However, the versions are regarded as comparable, and findings from the BDI-I can be generalized to the BDIII [24]. Finally, we had limited possibility to discuss our results in comparison with other reports. For the scarcity of outcome studies utilizing clinical measures in scoliotic patients [7], and unavailability of corresponding reports on mental health in people who participated in scoliosisspecific exercise programs-in opposition to general physical activity or exercising-we discussed studies on operated or braced patients. Moreover, other researchers typically used HRQoL rather than mental health measures. HRQoL instruments integrate the mental health domains within the general picture of a person's perceived health and well-being, with their physical and social dimensions. Screening for depression and mental health with specific instruments, such as the Beck inventory and Goldberg GHQ, is distinct from the measurements of HRQoL [40].

In conclusion, in this first outcome study of mental health of young adults with mild-to-moderate scoliosis, observed or treated with a program of scoliosis-specific exercises in adolescence, we have shown that in a long-term perspective people with mild scoliosis do not differ significantly from unaffected persons in terms of depression and other characteristics of general mental health: somatic symptoms, anxiety, insomnia, and social dysfunction. However, we found that participation in exercise treatment program in adolescence 
and spinal deformity even mild, or perhaps the awareness of the deformity, may have associations with depression symptoms. Thus, these findings correspond to the reports of a negative impact of scoliosis on mental health, regardless of its severity. Also, our observations may indicate that the decision to introduce a strenuous and demanding therapy should be made with caution, with proper evidence-based clinical judgment in terms of patients' needs and potential benefits, risks, and harm of an intervention.

\section{Ethical Approval}

The project has been granted ethical approval by the Senate Research Ethics Committee, University School of Physical Education, Warsaw, Poland, May 20, 2009, and has been registered at ClinicalTrials.gov, Registration no. NCT01384955.

\section{Conflict of Interests}

The authors declare that there is no conflict of interests regarding the publication of this paper.

\section{Authors' Contribution}

Maciej Płaszewski is the main author who obtained funding, planned and participated in designing and conducting the study, data collection, and analysis, performed the literature review, and drafted the paper. Igor Cieśliński participated in designing the study and performed the statistical analysis. Roman Nowobilski and Tomasz Kotwicki participated in conceiving and designing of the study. Jacek Terech and Mariusz Furgał participated in data collection and analysis. The authors read and accepted the final version of the paper.

\section{Acknowledgments}

This paper is a part of the Research Project DS.136, University School of Physical Education, Warsaw, sponsored by the Ministry of Science and Higher Education, Poland. The authors thank Doctor Ryszard Batycki for his involvement in interrater orthopedic examinations.

\section{References}

[1] M. Aebi, “The adult scoliosis," European Spine Journal, vol. 14, no. 10, pp. 925-948, 2005.

[2] S. L. Weinstein, L. A. Dolan, J. C. Cheng, A. Danielsson, and J. A. Morcuende, "Adolescent idiopathic scoliosis," The Lancet, vol. 371, no. 9623, pp. 1527-1537, 2008.

[3] M. A. Asher and D. C. Burton, "Adolescent idiopathic scoliosis: natural history and long term treatment effects. Scoliosis," 2006, 1 and 2, http://www.scoliosisjournal.com/content/1/1/2.

[4] A. J. Danielsson, I. Wiklund, K. Pehrsson, and A. L. Nachemson, "Health-related quality of life in patients with adolescent idiopathic scoliosis: a matched follow-up at least 20 years after treatment with brace or surgery," European Spine Journal, vol. 10, no. 4, pp. 278-288, 2001.
[5] F. Schwab, A. Dubey, L. Gamez et al., "Adult scoliosis: prevalence, SF-36, and nutritional parameters in an elderly volunteer population," Spine, vol. 30, no. 9, pp. 1082-1085, 2005.

[6] K. M. Kebaish, P. R. Neubauer, G. D. Voros, M. A. Khoshnevisan, and R. L. Skolasky, "Scoliosis in adults aged forty years and older: prevalence and relationship to age, race, and gender," Spine, vol. 36, no. 9, pp. 731-736, 2011.

[7] M. Tones, N. Moss, and D. W. Polly Jr., "A review of quality of life and psychosocial issues in scoliosis," Spine, vol. 31, no. 26, pp. 3027-3038, 2006.

[8] S. Matsunaga, K. Hayashi, T. Naruo, S.-I. Nozoe, and S. Komiya, "Psychologic management of brace therapy for patients with idiopathic scoliosis," Spine, vol. 30, no. 5, pp. 547-550, 2005.

[9] D. S. Sapountzi-Krepia, J. Valavanis, G. P. Panteleakis, D. T. Zangana, P. C. Vlachojiannis, and G. S. Sapkas, "Perceptions of body image, happiness and satisfaction in adolescents wearing a Boston brace for scoliosis treatment," Journal of Advanced Nursing, vol. 35, no. 5, pp. 683-690, 2001.

[10] K. J. Noonan, L. A. Dolan, W. C. Jacobson, and S. L. Weinstein, "Long-term psychosocial characteristics of patients treated for idiopathic scoliosis," Journal of Pediatric Orthopaedics, vol. 17, no. 6, pp. 712-717, 1997.

[11] S. L. Weinstein, L. A. Dolan, K. F. Spratt, K. K. Peterson, M. J. Spoonamore, and I. V. Ponseti, "Health and function of patients with untreated idiopathic scoliosis: a 50-year natural history study," Journal of the American Medical Association, vol. 289, no. 5, pp. 559-567, 2003.

[12] M. S. Goldberg, N. E. Mayo, B. Poitras, S. Scott, and J. Hanley, "The Ste-Justine adolescent idiopathic scoliosis cohort study-part II: perception of health, self and body image, and participation in physical activities," Spine, vol. 19, no. 14, pp. 1562-1572, 1994.

[13] A. J. Danielsson, R. Hasserius, A. Ohlin, and A. L. Nachemson, "Body appearance and quality of life in adult patients with adolescent idiopathic scoliosis treated with a brace or under observation alone during adolescence," Spine, vol. 37, no. 9, pp. 755-762, 2012.

[14] I. Helenius, V. Remes, T. Yrjönen et al., "Does gender affect outcome of surgery in adolescent idiopathic scoliosis?" Spine, vol. 30, no. 4, pp. 462-467, 2005.

[15] S. C. Mordecai and H. V. Dabke, "Efficacy of exercise therapy for the treatment of adolescent idiopathic scoliosis: a review of the literature," European Spine Journal, vol. 21, pp. 382-389, 2012.

[16] M. Romano, S. Minozzi, J. Bettany-Saltikov, F. Zaina, N. Chockalingam, and T. Kotwicki, "Exercises for adolescent idiopathic scoliosis," Cochrane Database of Systematic Reviews, vol. 8, Article ID CD007837, 2012.

[17] G. Groth-Marnat, Handbook of Psychological Assessment, Wiley, 5th edition, 2009.

[18] J. P. Vandenbroucke, E. von Elm, D. G. Altman, P. C. Gøtzsche, C. D. Mulrow, and S. J. Pocock, "Strengthening the Reporting of Observational Studies in Epidemiology (STROBE): explanation and elaboration," PLoS Medicine, vol. 4, no. 10, article e297, 2007.

[19] P. Edwards, I. Roberts, M. Clarke et al., "Increasing response rates to postal questionnaires: systematic review," British Medical Journal, vol. 324, no. 7347, pp. 1183-1185, 2002.

[20] K. Allen Greiner, "Adolescent idiopathic scoliosis: radiologic decision-making," American Family Physician, vol. 65, no. 9, pp. 1817-1822, 2002.

[21] S. Pużyński and J. Wciórka, "Measures of psychical trait," in Psychiatry, A. Bilikiewicz, S. Pużyński, J. Rybakowski, and J. 
Wciórka, Eds., pp. 453-538, Urban \& Partner, Wrocław, Poland, 2002, Polish.

[22] J. P. Robinson, P. R. Shaver, and L. S. Wrightsman, "Measures of depression and loneliness," in Measures of Personality and Social Psychological Attitudes, J. P. Robinson, P. R. Shaver, and L. S. Wrightman, Eds., pp. 201-204, Academic Press, San Diego, Calif, USA, 1991.

[23] P. Richter, J. Werner, A. Heerlein, A. Kraus, and H. Sauer, "On the validity of the Beck Depression Inventory. A review," Psychopathology, vol. 31, no. 3, pp. 160-168, 1998.

[24] A. T. Beck, R. A. Steer, R. Ball, and W. F. Ranieri, "Comparison of Beck depression inventories -IA and -II in psychiatric outpatients," Journal of Personality Assessment, vol. 67, no. 3, pp. 588-597, 1996.

[25] D. de Riddler, "Chronic illness," in Health Psychology, A. Kaptein and J. Weinman, Eds., BPS Blackwell, 2004.

[26] C. Jackson, “The general health questionnaire," Occupational Medicine, vol. 57, article 79, 2007.

[27] D. Goldberg and P. Williams, Assessment of Mental Health Based on the Examinations With the David Goldberg Questionnaires. A Handbook for Users of GHQ12 and GHQ28 Questionnaires, Occupational Medicine Institute, Łódź, Poland, 2001.

[28] S. Jackman, "PSCL: Classes and methods for R developed in the Political Science Computational Laboratory," Stanford, Calif, USA, R package version 1.04.1., 2001, http://pscl.stanford.edu.

[29] A. Zeileis, C. Kleiber, and S. Jackman, "Regression models for count data in R," Journal of Statistical Software, vol. 27, no. 8, 2008.

[30] W. N. Venables and B. D. Ripley, Modern Applied Statistics with S, Springer, New York, NY, USA, 2008.

[31] C. G. Helman, Culture, Health and Illness; Cultural Aspects of Stress and Suffering, Hodder Arnold, London, UK, 2007.

[32] D. Reichel and J. Schanz, "Developmental psychological aspects of scoliosis treatment," Pediatric Rehabilitation, vol. 6, no. 3-4, pp. 221-225, 2003.

[33] K. H. Bridwell, H. L. Shufflebarger, L. G. Lenke, T. G. Lowe, R. R. Betz, and G. S. Bassett, "Parents' and patients' preferences and concerns in idiopathic adolescent scoliosis: a cross-sectional preoperative analysis," Spine, vol. 25, no. 18, pp. 2392-2399, 2000.

[34] C. Götze, U. R. Liljenqvist, A. Slomka, H. G. Götze, and J. Steinbeck, "Quality of life and back pain: outcome 16.7 years after Harrington instrumentation," Spine, vol. 27, no. 13, pp. 1456-1464, 2002.

[35] P. J. Carek, S. E. Laibstain, and S. M. Carek, "Exercise for the treatment of depression and anxiety," International Journal of Psychiatry in Medicine, vol. 41, no. 1, pp. 15-28, 2011.

[36] A. Ströhle, "Physical activity, exercise, depression and anxiety disorders," Journal of Neural Transmission, vol. 116, no. 6, pp. 777-784, 2009.

[37] Scoliosis and Physical Activity Guideline Committee. Appropriateness of physical and sporting activity for those with scoliosis. Guideline, American Chiropractic Board of Sports Physicians, 2009, http://www.acbsp.com/.

[38] B. N. Green, C. Johnson, and W. Moreau, "Is physical activity contraindicated for individuals with scoliosis? A systematic literature review," Journal of Chiropractic Medicine, vol. 8, no. 1, pp. 25-37, 2009.

[39] R. C. Kessler, P. Berglund, O. Demler et al., "The epidemiology of major depressive disorder: results from the National Comorbidity Survey Replication (NCS-R)," Journal of the American Medical Association, vol. 289, no. 23, pp. 3095-3105, 2003.
[40] A. Leplège and S. Hunt, "The problem of quality of life in medicine," Journal of the American Medical Association, vol. 2, pp. 47-50, 1997. 


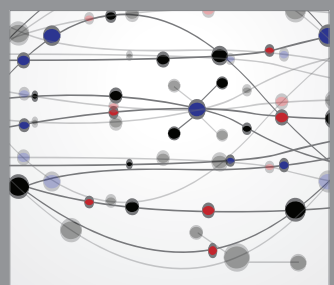

The Scientific World Journal
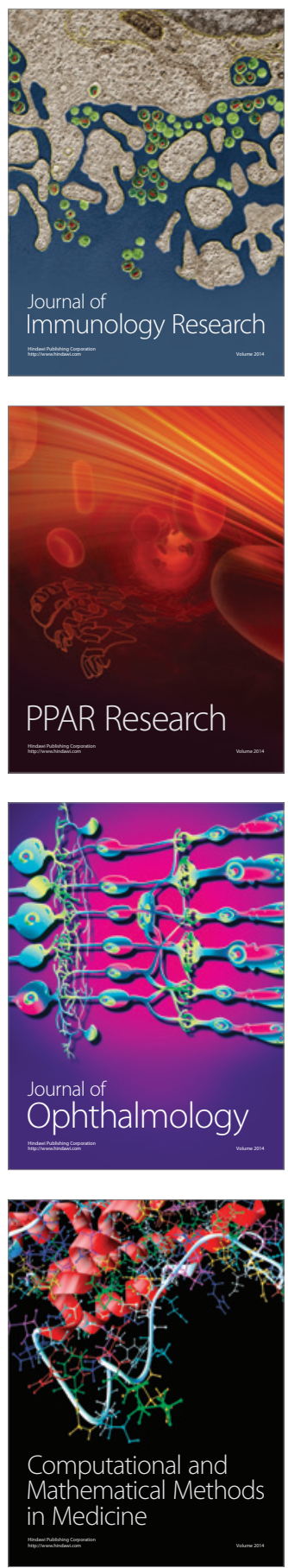

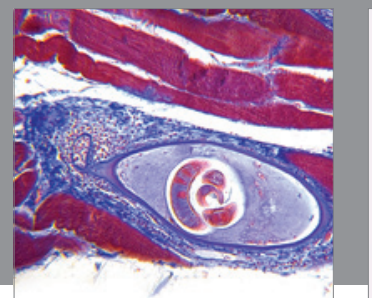

Gastroenterology

Research and Practice
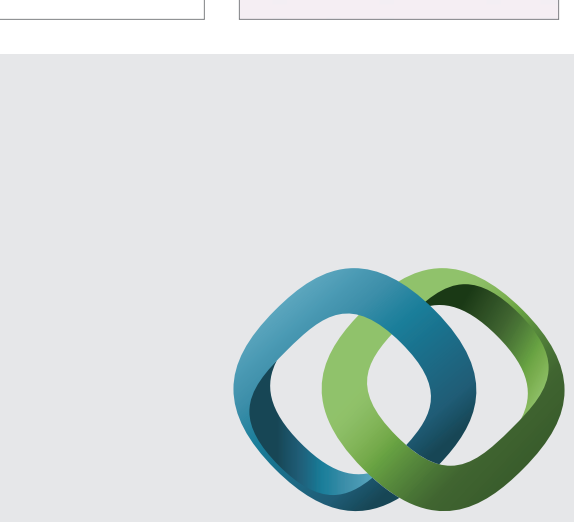

\section{Hindawi}

Submit your manuscripts at

http://www.hindawi.com
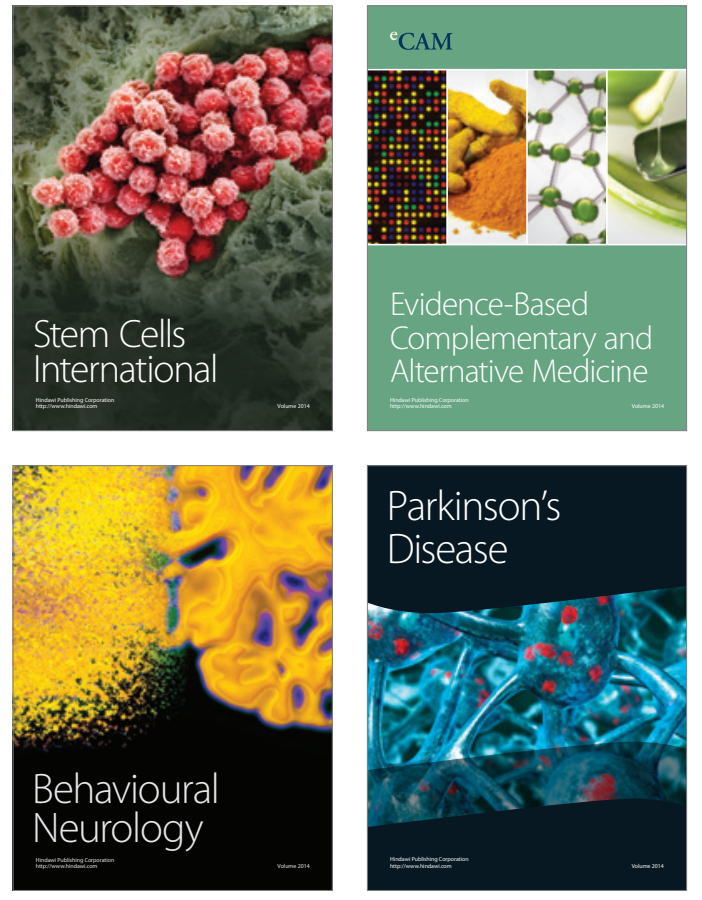
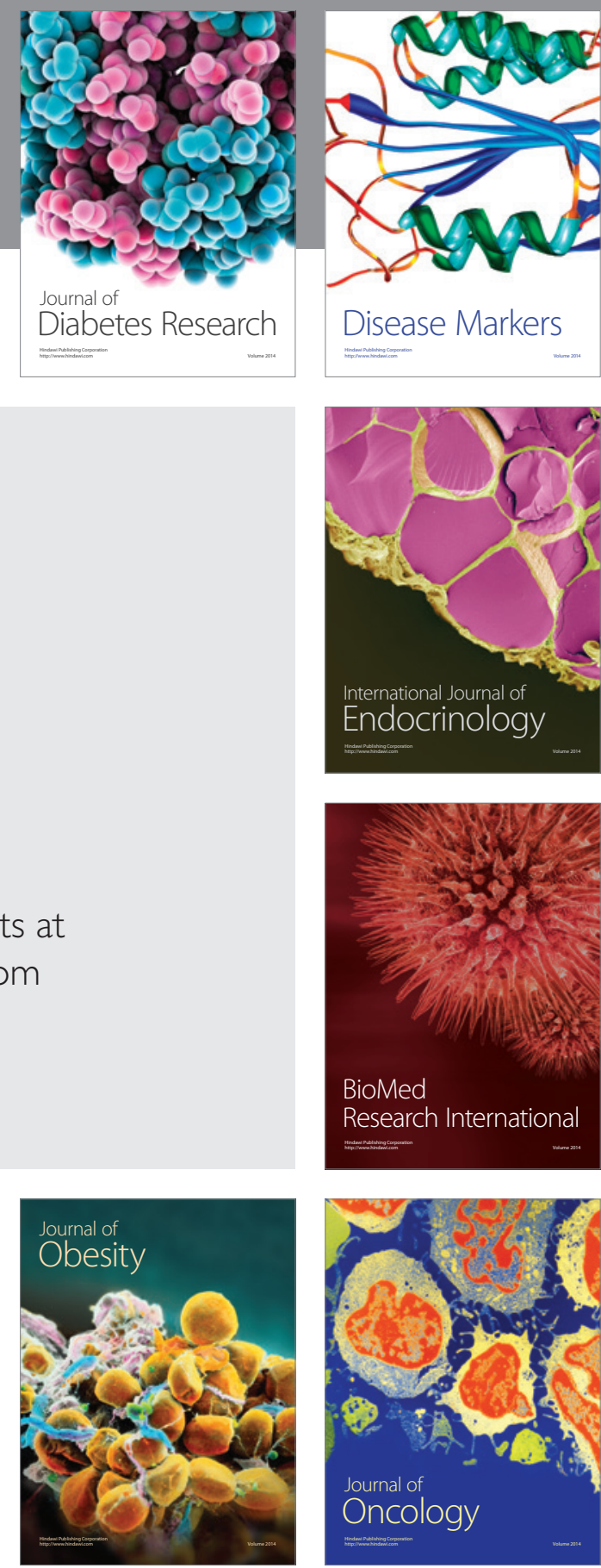

Disease Markers
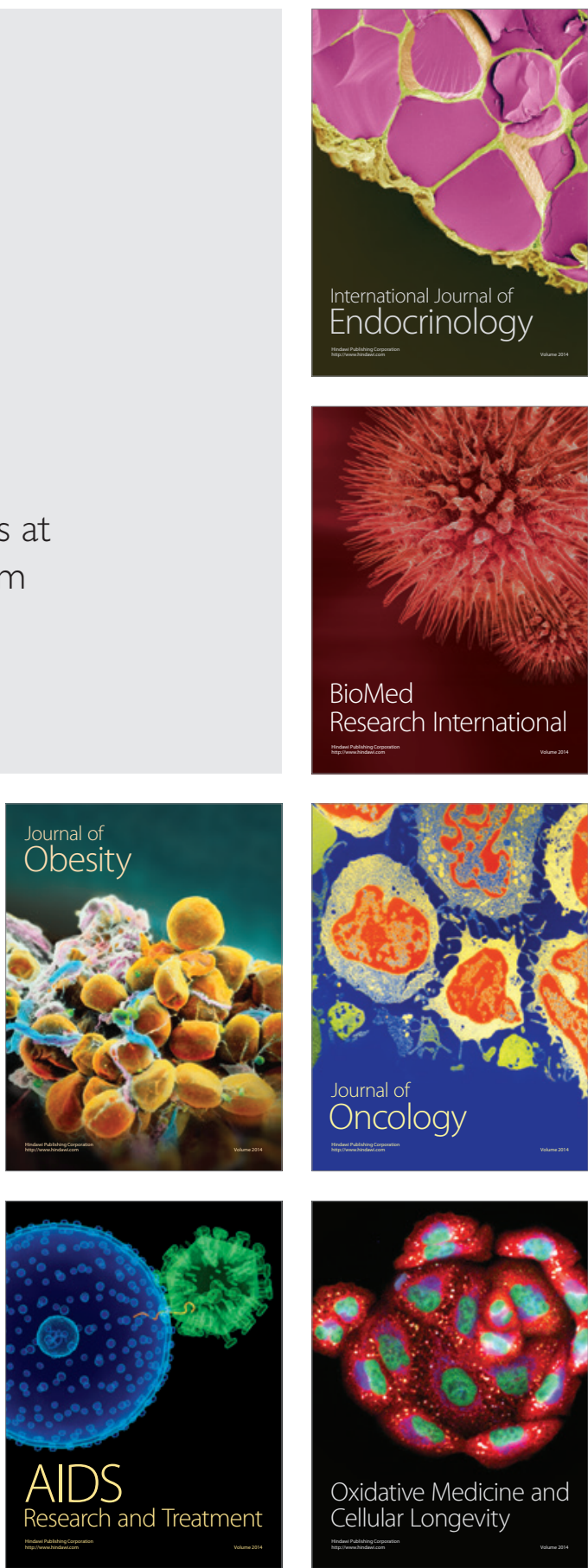